\title{
Vernacular Architecture in Michoacán. Constructive Tradition as a Response to the Natural and Cultural Surroundings
}

\author{
By Eugenia Maria Azevedo-Salomao* \\ Luis Alberto Torres-Garibay ${ }^{\dagger}$
}

\begin{abstract}
Various regions of Mexico (i.e., Michoacán) have a tradition in vernacular architecture with an important wealth heritage. Constructing in this way has a notable ecological quality that has benefits for its inhabitants and the natural and cultural surroundings. This work addresses the habitability of vernacular architecture in Michoacán, making the claim that the tradition of construction methods is anchored to the collective memory and the memory of the lived space. Therefore, memories express themselves as the truth of the past based in the present. In this way, the artisans of Michoacán gathered experience from past generations and distinguished themselves by the rational use of primary materials. With direct observation, surveys to users and literature based researches, selected examples of Michoacán are analyzed. The focus is on permanencies and transformations of the vernacular architecture of the region through the observation of social habits, uses, forms, construction, natural surrounding context and significance to society. The conclusion is reached by questioning why there is a gradual loss of vernacular heritage in the region. It is observed that a necessity for its permanence is required as well as the benefits of the implementation of new techniques that contribute to the regeneration of heritage buildings is emphasized. With sustainability in mind the incorporation of vernacular materials and construction methods together with contemporary solutions is also addressed.
\end{abstract}

\section{Introduction}

Vernacular architecture is the result of the process of collective creation in a geographical and cultural space. It is a communal construction, a special product of the way of life of human groups. These groups make regional materials their own, with local and timeless results that persist through generations with their own techniques, systems and procedures to edify.

In the state of Michoacán, Mexico, the physical and geographical diversity of the territory enabled the generation of an ample vernacular architecture and intangible heritage. This region has unique settlements because of its traditions, social organisation, customs and ways of life; always anchored to the physical conditions and local society.

The diverse climate characterizes the Michoacán region. Temperatures range from temperate in the Pátzcuaro's lake basin and Purépecha sierra to

\footnotetext{
* Professor, Michoacan University of Saint Nicholas of Hidalgo, Mexico.

${ }^{\dagger}$ Professor, Michoacan University of Saint Nicholas of Hidalgo, Mexico.
} 
extremely hot in Tierra Caliente and the coastal region. These diverse environments generate sensible adaptations of the architecture to its surroundings as well as the use of the local natural resources in accordance to the region's climate. In the central region of the state, the Purépecha indigenous culture still survives as a culture that maintains strong Mesoamerican ancestry (Figure 1).

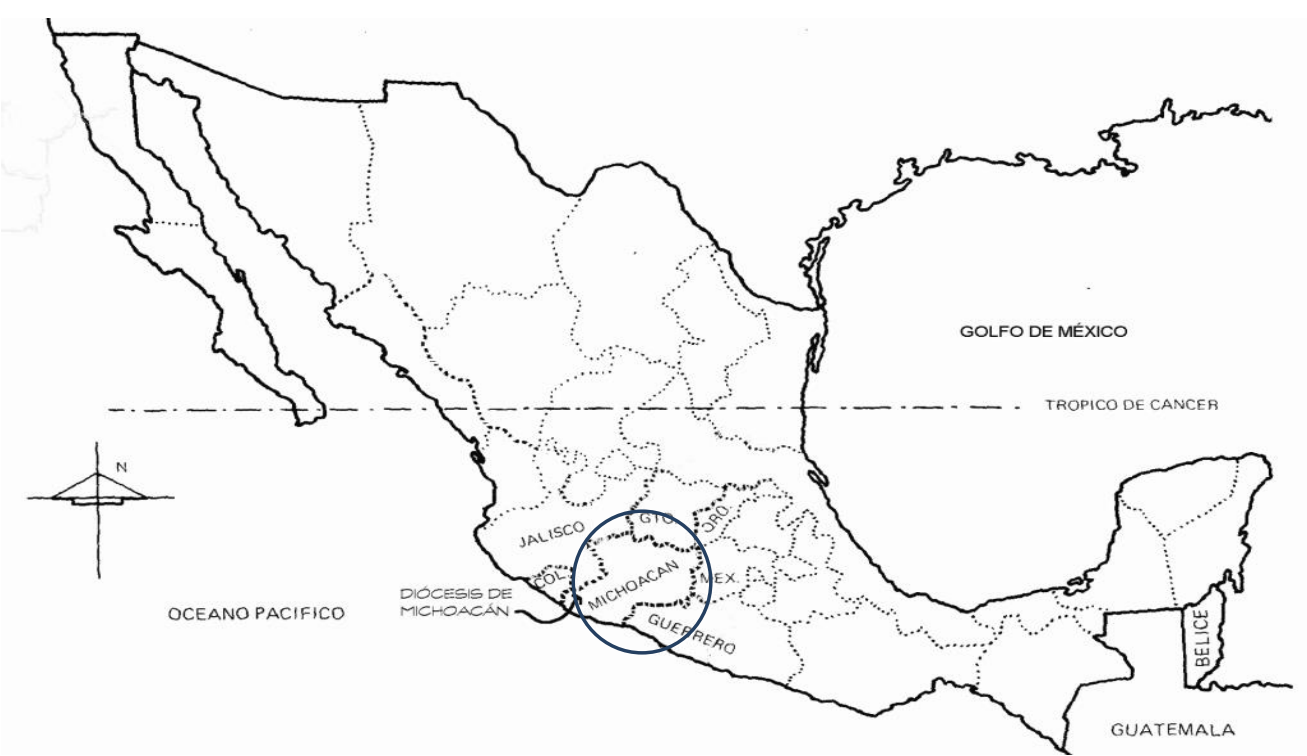

Figure 1. Mexican Map with the Geographical Localization of Michoacán State

Source: Torres Salomao Archive.

The purépechas together with other indigenous groups left an impact on the local construction tradition that was adapted to the climate of the location of each settlement. This tradition focused on the search of logical and simple solutions in construction. Differences among the methods of contruction are a function of the characteristics of every region. In this sense, spatial configuration resulted from a construction tradition and way of life that has endured for a long time.

The way of inhabiting and constructing imply gradual incidents in the permanence and change regarding the traditional michoacan's construction. They require architectonic space understanding as a product of the basic use necessities of the inhabitants with relation to day-to-day activities, aesthetics and materialization of habitable space. In addition, the natural and cultural surroundings are also involved in this equation, producing an ever-evolving cultural product that responds to individual and collective habits. In it, social and natural solutions coincide to satisfy functional and symbolic requirements born from the relationship between the user and space through the passing of time.

However, the diverse settlements of the Michoacán region are also vulnerable to transformations which affect their ancestry tradition in construction and put in risk the sustainability of the habitable space. The public 
policy is the main detractor of traditional construction and is mainly responsible for the observed transformations in these towns. With the slogan of "a better quality of life" for the indigenous population of Mexico, they have changed and devalued the indigenous values and traditional inhabitation (Figure 2).

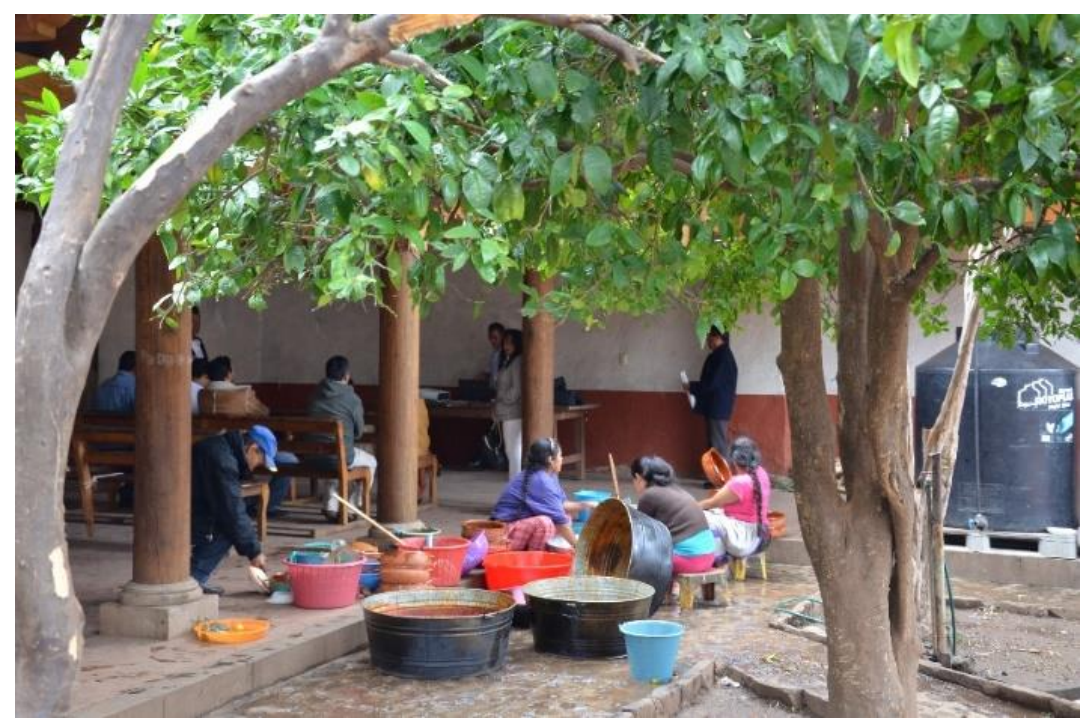

Figure 2. Food Preparation in the Santa Fe Hospital, Pátzcuaro's Lake Basin Source: Torres Salomao Archive.

This work addresses the idea that with habitable spaces, relationship between the diverse systems is materialized, in other words, the relationship between the environment and our social and cultural life. In this way, the identification and understanding of the dependencies between social, environmental and economic dimensions of habitable spaces allows the assessment of the present well-being. It also allows the assessment of sustainability for the future and preservation of natural and cultural heritage.

\section{The Concept of Habitability and Response to Natural and Cultural Surroundings}

To exemplify the concept of habitability, the purépecha culture is used as a case of study because of the importance they give to the relationship between form of life and the natural surroundings where they live. ${ }^{1}$ This way of being, as explained by Heidegger, is normally linked to vernacular cultures in which their settlements come from rural tradition with very small variability throughout time. These cultures are respectful of the surrounding nature and are reticent to any kind of change that disagrees with the location. ${ }^{2}$

1. Paul Levy and Marion Segaud, Antropologie de l'espace [Anthropology of space,] (Paris: Centre George Pompidou, 1983).

2. Martin Heidegger, Conferencias y artículos (incluye: Construir, habitar, pensar) [Conferences and items (includes: Build, live, think),] (Barcelona: Ediciones de Serbal, 1994). 
In the purépecha culture inhabitation is mainly outdoors. However, indoor space is also important as a complimentary element of their daily life. Their social practices determine conception and modes of space; likewise, these conceptions and modes of space also determine practice. Through the use of space, the identification of the materialized surroundings traduced into behavioral patterns and special models are achieved. Norberg-Schulz recognises these patters developed by the individuals in their interaction with the environment, and names them, 'existential space'. This existential space reflects the structure of the surrounding environment, in constant regeneration by necessity and desire. ${ }^{3}$

It is possible to state that social habit and use lasts more than the form and materiality of space. Just as a family is identified to the space that it inhabits, a community is shaped in communal spaces in a settlement. In ancient cultures, elements of nature had a special meaning and, because of this, it is normal that the imaginary of a community remains dependant to an emblematic space loaded with significance.

A conclusion can be reached with the idea that habitability is the way in which spaces are adapted for their utility in accordance to the way of life of society. Inhabitation is the purpose of architecture and as such must respond to physical, biological, psychological and cultural necessities of the human being. ${ }^{4}$

In the case of the Michoacán region during the Mesoamerican period, an outdoor open life was common. Inhabitation was achieved in complete harmony with nature, and this tradition endured to the viceregal period. During this period, despite all changes generated by new ways of inhabitation, exterior space continued as the most important feature for daily activities (Figure 3).

The quality of life was an integral concept of open and closed spaces in the relationships of the house. In fact, the interior space is very simple and has only essential utensils and furniture. This space is only thought as a sleeping and as a spiritual space for prayer and is sufficient to ensure these activities. All other human biological, social, recreational and artistic activities of this indigenous group are done in the open space. As stated by Carlos Chanfón, the Mesoamerican space organization mythically joined constructed spaces with natural spaces. 5

3. Christian Norberg-Schulz, Existencia, Espacio y Arquitectura [Existence, Space and Architecture,] (Barcelona: Editorial Blume, 1975), 9.

4. Jose Villagran, Estructura teórica del programa arquitectónico [Theoretical structure of the architectural program,] course, (Mexico City: El Colegio Nacional, August 1963), 295.

5. Carlos Chanfon Olmos and his collaborators in the HAYUM project amply developed this topic. 


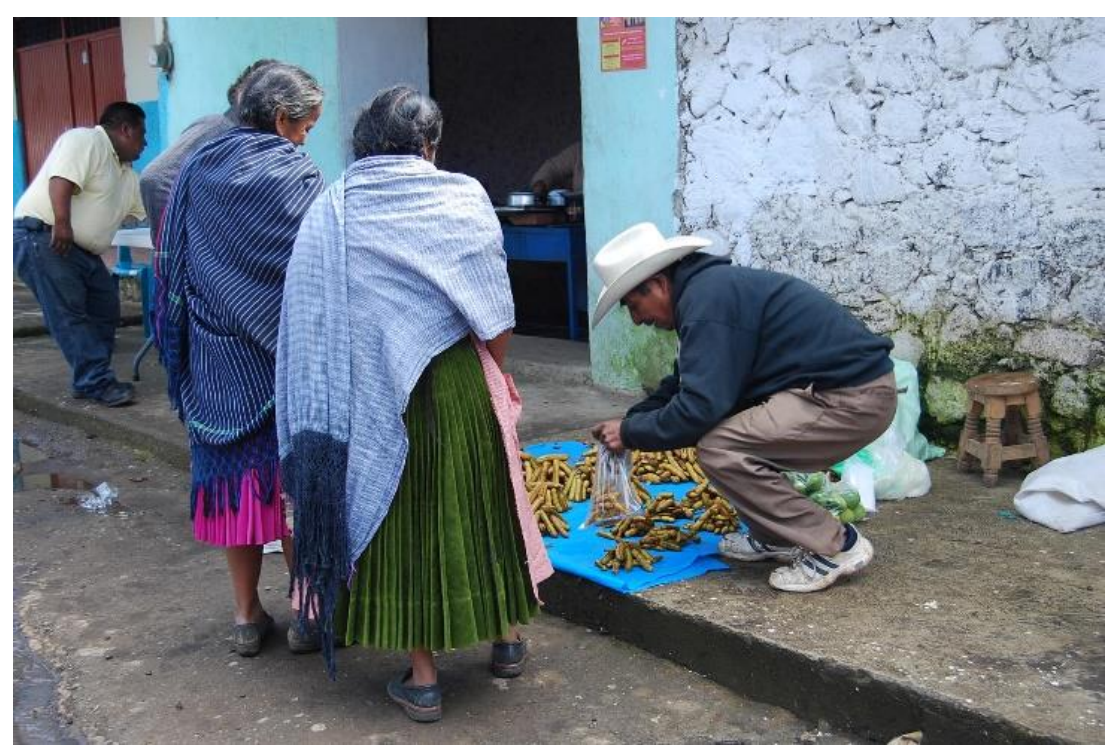

Figure 3. Commercial Activities in San Lorenzo, Purépecha Sierra Source: Torres Salomao Archive.

Following the previous idea and as a permanence in the use of space, edifications are located inside a solar, (for example a piece of land of big dimensions) preferably giving their back or their side to the street with the objective of creating a central interior patio. This patio is related to the portico of the house and is connected to the harvesting area.

In the purépecha culture, day-to-day activities were done in the open air and inside the porch (for example a semi-open space). These activities included tasks such as the preparation of food for its storage (i.e., threshing of corn for its storage in the top section of the house), handcraft artisanal activities (i.e., knitting) and communication with other family members. The porch, linked to the sleeping and praying room integrates itself to the outdoor space and is related to the patio.

The patio is the generating space of all activities, it is related to the bedroom, the porch, the kitchen and all other spaces that constitute external areas such as the henhouse, the latrine and the ekuarho, ${ }^{6}$ a space destined for the harvesting of corn and other food as well as fruit trees; activities of the dayto-day life (Figure 4).

6. The ekuarho has an ample meaning for the purépecha culture. In this case it is referred to the free space of the solar left for harvesting of products for self-consumption. 


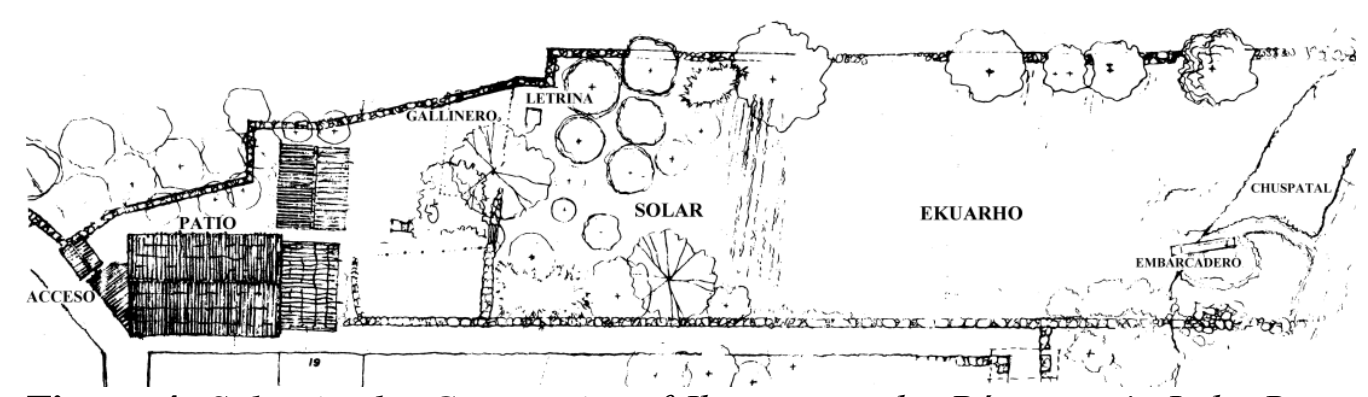

Figure 4. Solar in the Community of Ihuatzio in the Pátzcuaro's Lake Basin Region

Source: Ramirez, 1990, p.364.

In this way, the house of the purépecha is the integral space conformed by rooms and the external areas where diverse activities are developed; all of them articulated and related with the patio as a generator of all activity.

In other cases the house evolved and was made with many conjoined enclosures of one, two or three rooms, where more were added as the family grew. In this way, porch corridors were created that allowed the transition between open and closed spaces, allowing for familiar activities. ${ }^{7}$

As it can be observed, the habitable purépecha space is not an isolated fact alienated form a cultural life and determined only by some distinctive aesthetic characteristics and style, ${ }^{8}$ its role as a cultural material object gives it testimonial properties of a cultural vital element.

The purépecha habitat evidences a profound knowledge of the environment, which has been transmitted from generation to generation. In its manufacturing organic materials such as dirt and wood are dominant and have their antecedents in the Mesoamerican purépecha housing to which Europeans also contributed elements as part of a miscegenation cultural process. It is an architecture adapted to the physical and geographical location where it is located. It includes actions that have endured over the years but with obvious modifications originated from technological advancement or cultural patterns imported from other places. Community and social familiar ways of life are also expressed, perpetuating life in the open space, characteristic of the Mesoamerican world and persistent to our days. ${ }^{9}$

7. Romero Esperanza Ramirez, Catálogo de Monumentos y sitios de Pátzcuaro y la región lacustre [Catalogue of Monuments and Sites of Patzcuaro and the lake región,] (Morelia: Universidad Michoacana de San Nicolás de Hidalgo/Gobierno del Estado de Michoacán, 1990), 348.

8. Hector Alvarez, Arquitectura habitacional del siglo XVIII en Pátzcuaro, análisis arquitectónico de cinco casos [Eighteenth-century residential architecture in Patzcuaro, architectural analysis of five cases,] master thesis (Morelia: Facultad de Arquitectura, UMSNH, 2002), 6-7.

9. Eugenia Azevedo, La vivienda purépecha. Historia, habitabilidad, tecnología y confort de la vivienda purépecha [The Purepecha housing. History, habitability, technology and comfort of home Purepecha,] (Morelia: Universidad Michoacana de San Nicolás de Hidalgo, Coordinación de la Investigación Científica. Consejo Estatal de Ciencia y Tecnología, 2008), 66. 


\title{
Work Organization and Constructive Characteristics of the Vernacular Architecture in Michoacán
}

\author{
Work Organization
}

The edification process in vernacular houses is a communal act. Families gather to construct or more commonly substitute the roof of the house in a ritual act that is followed at its end with a celebration.

This communal organization form has its antecedent in the political Mesoamerican structure of the purépecha culture. In this structure, all activities were performed with specialized groups for each task and with the direction of a steward that solved all necessities of the community.

In construction, the participation with faenas (for example tasks) was the most effective strategy. In them, tasks were assigned by a work coordinator and with concordance to the ability of the artisan, which made each individual a contributor to the community. In other cases, participation was made in species by donating materials needed in the work. This organization allows every participant to train for construction related works and the dominium of the technique for construction (Figure 5).

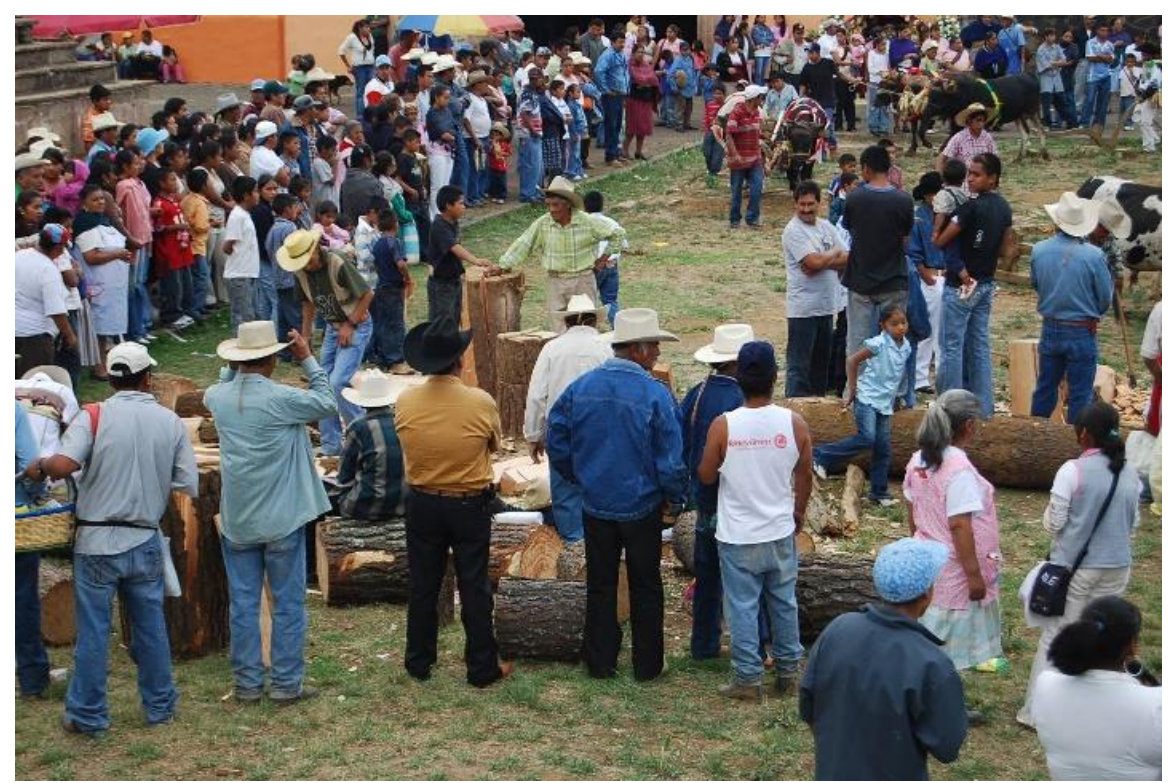

Figure 5. Communitarian Work in Sevina, Purépecha Sierra

Source: Torres Salomao Archive.

For the Purépechas, tools had high meaning, they were familiar possessions and family members were permanently linked to them. Since birth, tools formed part of an infant's life; they were common components of the domestic scenery. The observation from an early age of their handling favored the learning of their use. Here artistic freedom was promoted with the free play 
of disciplined imagination through long years of observation and practice. ${ }^{10}$ This sense of knowledge appropriation through familiar and everyday observation resulted in an architecture with adaptive and integral configurations to the physical surroundings and the geography of the environment as common denominators.

\section{Constructive Characteristics of the Vernacular Architecture}

Housing in the regions of the Pátzcuaro's lake basin (e.g., Uruapan region, lake basin of Zacapu and Cuitzeo) was developed taking into account the temperate climate with adobes, stone and wood. This region has temperatures between $12{ }^{\circ} \mathrm{C}$ and $24{ }^{\circ} \mathrm{C}$; it has altitudes of between 1,140 and 1,990 meters over sea level and is a forest region with abundant rain during summer and with rain towards the end of October, with its dry season from November to May. The masonry foundations were elaborated with the abundant volcanic stones of the region. The walls were made with adobes laid in rope hoist and in coals to achieve a thickness of better stability. For the reinforcements, bracketed wood was used to form enclosures and for the wall top trawls. Roofs were elaborated with timber trusses and covered with shingles. Facings were either left without covering or flattened with mixtures of clay and straw. In many cases the rooms had at their front porches, pillars over stone bases and beams over wooden supports (Figure 6).
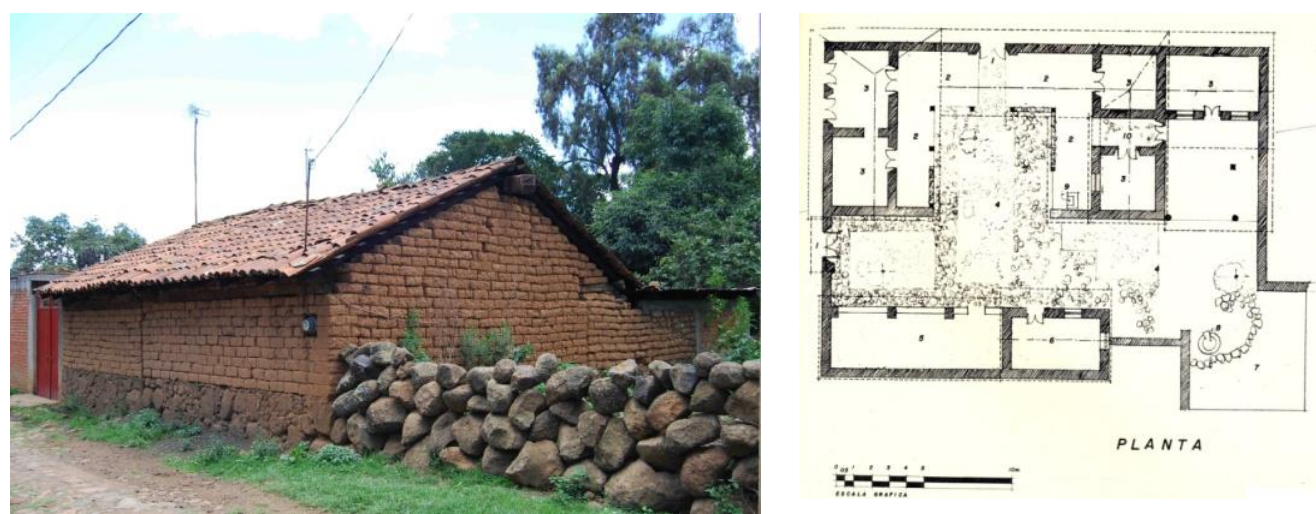

Figure 6. Traditional House at San Bartolo Pareo in Pátzcuaro's Lake Basin Region

Source: Torres Salomao Archive.

In the Purépecha sierra region of cold-temperate climate adobe houses were also built. The region's temperature rounds the $16{ }^{\circ} \mathrm{C}$ with altitudes over 2,500 meters over sea level. This is the reason why trojes (for example wooden built houses) were a more adequate solution to endure the colder weather. The spaces in a troje are three; the porch at the front for familiar and social activities, the sleeping and praying room to place the altar and store equipment,

10. Agustin Jacinto, Mitología y Modernización [Mythology and Modernization,] (Gobierno del Estado de Michoacán, Zamora: El Colegio de Michoacán, 1988), 57 
and the tapanco (for example a type of attic) at the top between the roof and the cover to store the seeds (Figure 7).

The domestic troje characterizes the historic towns mainly in the Purépecha sierra. Because of its flexible, expressive and functional characteristics, this constructive system has a high meaning in the cultural development of the state of Michoacán. Its special virtues and advantages relative to its simple construction procedure make them the most recognized buildings regarding special design and technique.

The troje is built elevated from the ground over stone bases. Over these, timber beams and planks are assembled to form the main floor, walls and roof structure. The cover is made with four inclined sections of high steepness. The roofs are built with trusses and purlins covered with tejamaniles (for example wooden shingles) spliced together with tejocote (e.g., a species of hawthorn) thorns and maguey (e.g., also known as agave or century plant) fibre strings. ${ }^{11}$
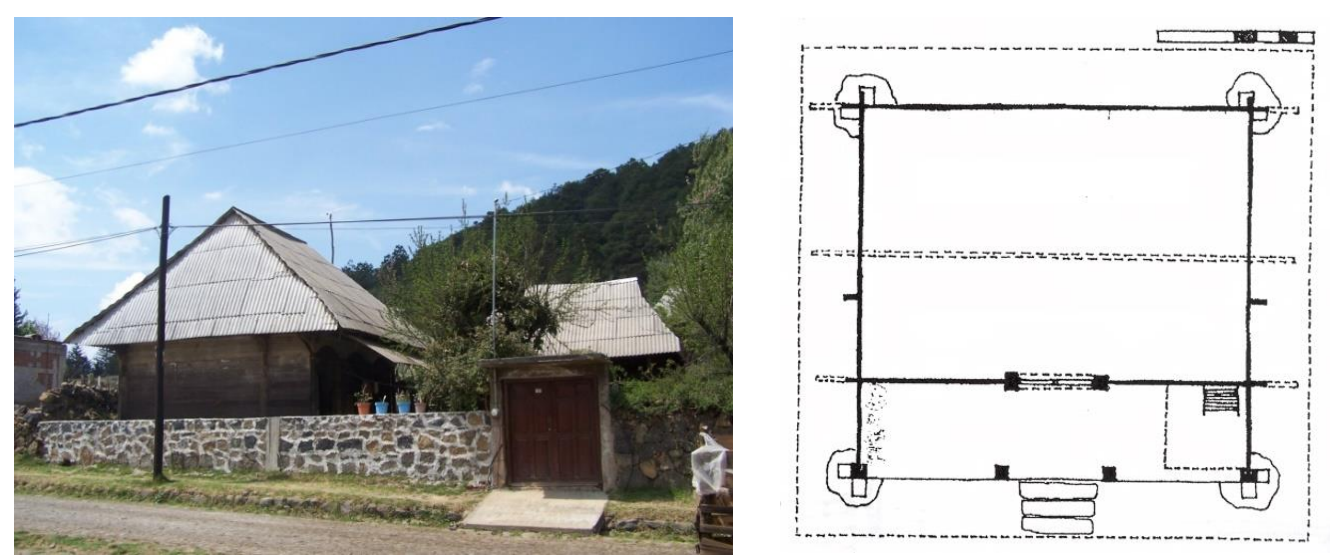

Figure 7. Wooden House Named Troje at Corupo in the Purépecha Sierra Source: Torres Salomao Archive.

All the system is assembled and, in many cases, the front of the troje is prolonged in its base and enclosed to form a porch with two or four pillars and wooden bases. The entrance is left in the middle, being the only access to the house.

In the basin of the Balsas river in the Tierra Caliente region and in the coastal region, the housing architecture was adapted for a hot-dry climate. Temperatures in this reagion vary from $40{ }^{\circ} \mathrm{C}$ to $50{ }^{\circ} \mathrm{C}$ and variable altitudes ranging from 100 to 2,500 meters over sea level. Weather is semi-dry and tropical with light rain during summer. Houses in these regions are constructed with light materials, indigenous to the region. Solutions vary; in many cases rooms were built with adobe, following the tradition already described, but

11. In recent times, tejocote thorns have been substituted with steel nails and maguey fibre strings with annealed wire. The splicing of tejamanil was done by joining moist (to avoid cracks) wooden leafs with nailed thorns and reeled off with the maguey strings with a twoturns knott, named as the nudo de puerco in the region. Because tejamanil is a split leaf with grooves, it propitiates an ideal surface for rain circulation. This is the reason for its vertical assembling. 
combining these structures with lighter inclined covers. The materials used for the roof include thin roundwood or reeds to allow the natural ventilation and circulation of air into the interior.

In other cases, the solution was to stick wooden columns at convenient distances to form a vertical structure. Between each column horizontal rods were woven to form jalousie walls. Over these light walls a mixture of mud combined with straw or a similar product was laid to create a flattened surface. The cover is settled over the columns forming two slopes covered with straw, palm leaves or tiles. This variant known as bajareque is very versatile since it allows certain areas to be left without the clay flattening allowing air circulation to ventilate the interior of the houses (Figure 8).
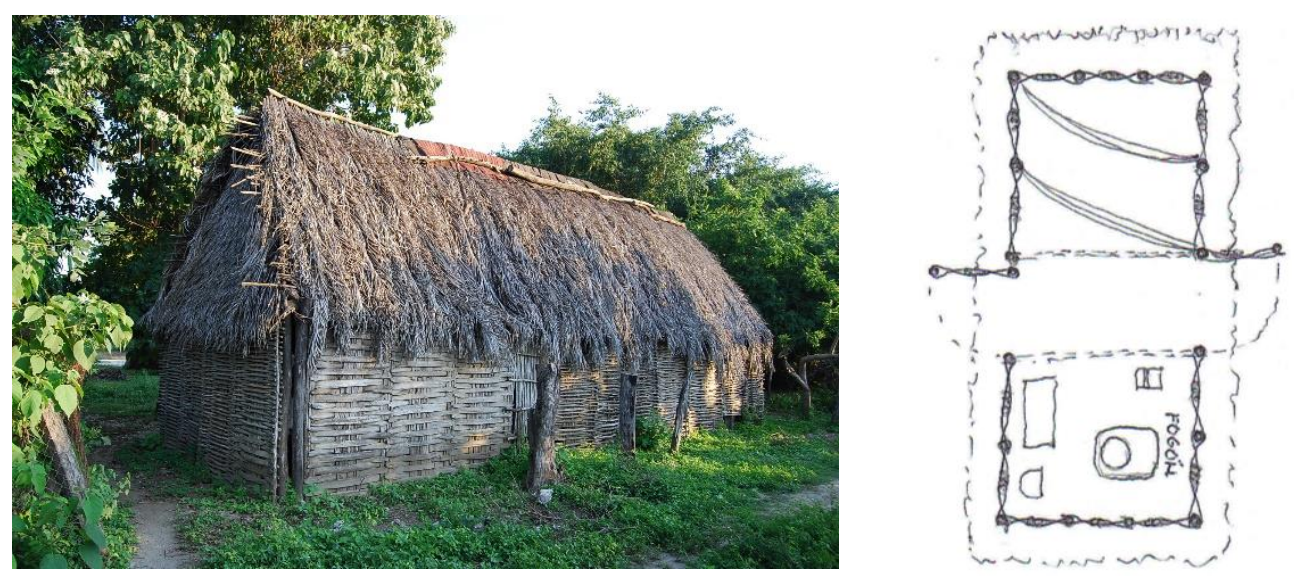

Figure 8. House in Maruata in the Coastal Region of Michoacán Source: Torres Salomao Archive.

\section{Rational Use of Materials and their Adaptation}

As can be observed, developed vernacular architecture in Michoacán has always taken into account the physical and geographical environment where it is developed. The environment is fully understood and the architecture has adapted to it. Selected materials are natural materials that are processed in a rational manner so they can be used without harming or modifying the environment. The earth, stone, wood and plant products used to construct, constitute supplies used in a sustainable moderate way. Necessary time for their recovery is considered by the indigenous communities and the constructions gradually form part of the local environment where they are installed.

Rooms constructed with stones, adobes and wood are used in a selfsufficient manner. The existent stone of the location is used; similarly, the adobes are prepared with water, dirt and plant products from the same location. These materials are mixed together and through casts the pieces that will be part of the walls are elaborated. The region has many forests, which facilitates the use of wood in different forms. Timber is used as beams to construct the covers and enclosures of openings and windows and the whole genre of 
structural components. The tejamanil and the clay cooked tiles form part of the elements that identify this architecture as anchored in sustainability because of the recovery possibilities they entail.

Wood houses such as the troje, constructed totally from pine trees of the region, are completely assembleable. Walls are configured with thick articulated wooden boards and the main structure is constructed with wooden pillars and beams, which are also assembled. In this way, the whole system can be completely unassembled and transferred to another location easily.

The bajareque houses of the warm regions use lighter materials of quicker recovery since walls are fabricated with roundwood and with interwoven rods that are found in the forest.

As can be observed, the rationally used products are framed in the field of sustainability because this traditional constructive system allows the recovery of the environment. Materials used for construction are prepared by the actual inhabitants. Further into this idea, wood is cut according to the age of the timber to obtain an adequate material. Other materials from the region like palm trees, branches and vines are cut for their use as roof covers. This allows a quick vegetation recovery. Stone and earth are obtained in the same region were houses are constructed, making the whole system highly sustainable.

It is also important to note the adaptation of the spaces with the use of natural systems and with regards to the climate of the regions where they are built. In temperate regions, rooms are closed and without windows. ${ }^{12}$ Only one access door exists since the room is only used for sleeping and praying. The roof with beams and tejamaniles provides a high grade of protection against the cold. In the warm regions, the bajareque house is totally adequate to allow cross ventilation inside the enclosed spaces to condition the interior as a fresh ambient that offers protection from the sun.

\section{Permanencies and Transformations}

Permanencies in the purépecha way to construct are linked to the way of inhabitation of the spaces; manifest aspects of their anchoring, with results in space. From interacting relationships between the techniques, used materials, organization forms and spatial necessities vernacular architecture remains in close relationship to logical solutions in scale and proportion. The solutions are commonly adjusted to the structural possibilities of each of the selected and prepared materials for the different construction systems and in concordance to the sought space. This interactive relationship originated habits and constructive conditions that with time gave way into tradition and formed part of an ample heritage of cultural permanencies in edification. The space for itself, is designed with a rectangular or square shape, and crowned with a cover of inclined slopes.

12. Azevedo, La vivienda purépecha. Historia, habitabilidad, tecnología y confort de la vivienda purépecha, 2008, 58. 
The constructive tradition in all the regions of the Michoacán territory retained the indicated criteria to set up its spaces. Nevertheless, the apparition of new ideas in the way of inhabitation and the introduction of new materials and techniques to edify have initiated in the vernacular construction, a gradual process of substitution in the community. However, permanencies referred to the spatial solutions are quite notorious regardless of the changes in constructive solutions.

Another aspect worth noting in the development of the vernacular architecture of the region is the dominium of technique and its material relationship of transformation and elaboration of systems to edify. The Construction with natural materials offered a panorama full of possibilities for the artisan to act upon. The artisan acquired the capacity and dominium of technique to construct, with the advantage of a full dominium of systems. Because of this reason, constructive and spatial results reached a total coherence since the own users designed and constructed their house with their interests and necessities of habitability in mind. This is why the knowledge of techniques and the adequate use of tools were fundamental. ${ }^{13}$

The introduction of new materials from modern technological advances has propitiated dependence to specialized construction processes, an aspect that has motivated the oblivion of traditional techniques for construction.

Transformations can also be seen in other aspects that relate to changes in the way of life. In some locations vernacular architecture has opened its doors to new spaces with uses related to modern models. This has modified the traditional way of the inhabitation of space, which in turn originates changes with imitation of urban architecture of more developed cities with a different occupation way. This has impacted historic towns.

\section{Conclusions}

It can be stated that the vernacular architecture constructive tradition in Michoacán has a strong tendency to preserve a constructive pattern and the use of space. However, in many localities of the state, the way of life is changing.

These changes, palpable in the shapes, dimensions, materials and constructive systems are not compatible with the uses and habits of the indigenous inhabitants and neither with the environment where they live. Governmental programs do not adjust or understand the indigenous way of life and encourage the introduction of models that use material resources unrelated to the natural environment and real necessities of the inhabitants.

The observed changes in the architecture are not linked to an adequate transformation processes. Nevertheless, formal, functional, spatial, material and environmental characteristics of the architecture are manifested and reflect a search to include in the life of the indigenous inhabitant elements that propitiate satisfaction and improvement of their life conditions. Many times,

13. Jacinto, Mitología y Modernización, 1988, 44. 
this is not achieved, but most worrisome is the fact that their way of life accustomed to open spaces, has been modified to living in a different way.

Even if technology has demanded new solutions, it is possible to observe permanencies in constructed products that have retained some special patterns even with the new materials.

These transformations demand, by nature, a reflection around the necessity to implement new systems with techniques devised from the perpetuated knowledge of the vernacular architecture. This has the aim of choosing integral transformations to constructive tradition and to respond thoroughly to the natural and cultural environment of the region. The idea is to choose changes that protect natural areas that support these communities and warrant the permanence and even the expansion of this architecture anchored in sustainability.

\section{Bibliography}

Alvarez, Hector. Arquitectura habitacional del siglo XVIII en Pátzcuaro, análisis arquitectónico de cinco casos [Eighteenth-century residential architecture in Patzcuaro, architectural analysis of five cases.] Master thesis. Morelia: Facultad de Arquitectura, UMSNH, 2002.

Azevedo, Eugenia. La vivienda purépecha. Historia, habitabilidad, tecnología y confort de la vivienda purépecha [The Purepecha housing. History, habitability, technology and comfort of home Purepecha.] Morelia: Universidad Michoacana de San Nicolás de Hidalgo, Coordinación de la Investigación Científica. Consejo Estatal de Ciencia y Tecnología, 2008.

Heidegger, Martin. Conferencias y artículos (incluye: Construir, habitar, pensar) [Conferences and items (includes: Build, live, think).] Barcelona: Ediciones de Serbal, 1994.

Jacinto, Agustin. Mitología y Modernización [Mythology and Modernization.] Gobierno del Estado de Michoacán, Zamora: El Colegio de Michoacán, 1988.

Levy, Paul and Marion Segaud. Antropologie de l'espace [Anthropology of space.] Paris: Centre George Pompidou, 1983.

Norberg-Schulz, Christian. Existencia, Espacio y Arquitectura [Existence, Space and Architecture.] Barcelona: Editorial Blume, 1975.

Ramirez, Romero Esperanza. Catálogo de Monumentos y sitios de Pátzcuaro y la región lacustre [Catalogue of Monuments and Sites of Patzcuaro and the lake región.] Morelia: Universidad Michoacana de San Nicolás de Hidalgo/Gobierno del Estado de Michoacán, 1990.

Villagran, Jose. Estructura teórica del programa arquitectónico [Theoretical structure of the architectural program.] Course. Mexico City: El Colegio Nacional, August 1963. 
